\title{
Discriminating between chronic fatigue syndrome and depression: a cognitive analysis
}

\author{
RONA MOSS-MORRIS ${ }^{1}$ AND KEITH J. PETRIE \\ From the Health Psychology Research Group, Faculty of Medical and Health Science, The University of \\ Auckland, Auckland, New Zealand
}

\begin{abstract}
Background. Chronic fatigue syndrome (CFS) and depression share a number of common symptoms and the majority of CFS patients meet lifetime criteria for depression. While cognitive factors seem key to the maintenance of CFS and depression, little is known about how the cognitive characteristics differ in the two conditions.

Methods. Fifty-three CFS patients were compared with 20 depressed patients and 38 healthy controls on perceptions of their health, illness attributions, self-esteem, cognitive distortions of general and somatic events, symptoms of distress and coping. A 6 month follow-up was also conducted to determine the stability of these factors and to investigate whether CFS-related cognitions predict ongoing disability and fatigue in this disorder.
\end{abstract}

Results. Between-group analyses confirmed that the depressed group was distinguished by low self-esteem, the propensity to make cognitive distortions across all situations, and to attribute their illness to psychological factors. In contrast, the CFS patients were characterized by low ratings of their current health status, a strong illness identity, external attributions for their illness, and distortions in thinking that were specific to somatic experiences. They were also more likely than depressed patients to cope with their illness by limiting stress and activity levels. These CFS-related cognitions and behaviours were associated with disability and fatigue 6 months later.

Conclusions. CFS and depression can be distinguished by unique cognitive styles characteristic of each condition. The documented cognitive profile of the CFS patients provides support for the current cognitive behavioural models of the illness.

\section{INTRODUCTION}

Chronic fatigue syndrome (CFS) is a disorder of uncertain aetiology, characterized by debilitating fatigue which has been present for at least 6 months (Fukuda et al. 1994). The idiopathic nature of CFS has led to an ongoing debate as to the organic or functional aetiology of this disorder. Those favouring an organic cause have linked CFS to viral pathogens, muscle abnormalities, and immunological and neurological changes. While a number of abnormalities have been documented in CFS groups,

1 Address for correspondence: Dr Rona Moss-Morris, Health Psychology Research Group, The Faculty of Medical and Health Science, The University of Auckland, Private Bag 92 019, Auckland, New Zealand. no clear distinguishing organic agent has been found (Evengard et al. 1999). The lack of a defining pathophysiology has led others to suggest that CFS is a somatic form of depression (Manu et al. 1993).

The argument for CFS as a form of depression is based on the significant overlap between these two disorders. CFS shares a number of cardinal symptoms with depressive disorders including extreme fatigue, sleep disturbance, diminished concentration, and problems with memory. In fact, up to $85 \%$ of CFS patients report depressed mood as a key symptom (Komaroff \& Buchwald, 1991) and around two-thirds of patients meet lifetime criteria for depression (Abbey, 1996). Studies comparing CFS patients to patients with a range of medical illnesses, including rheu- 
matoid arthritis, multiple sclerosis, neuromuscular disorders and myopathies have invariably reported significantly higher rates of depression in CFS (Wessely \& Powell, 1989; Katon et al. 1991; Wood et al. 1991; Pepper et al. 1993; Johnson et al. 1996).

Despite this overlap, there is evidence that relevant differences may exist. Studies of the neuroendocrine system have demonstrated significantly different physiological abnormalities in each of these disorders, although results have not always been consistent (Schwartz et al. 1994; Cleare et al. 1995; Goldstein et al. 1995; Fischler et al. 1996). In addition, unlike depressed patients, CFS patients do not seem to respond to antidepressant medication (Natelson et al. 1996; Vercoulen et al. 1996).

A closer look at the psychological symptomatology of these groups shows that CFS patients consistently report lower mean scores on depression inventories, although their scores are still within the depressed range (Hickie et al. 1990; Johnson et al. 1996; Wessely \& Powell, 1989). These differences are largely accounted for by depressed patients scoring significantly higher on the self-reproach or cognitive symptoms including feelings of guilt, low selfesteem, and suicidal ideation (Powell et al. 1990; Johnson et al. 1996).

A more detailed investigation of the cognitions of the two groups may provide another avenue to determine whether depression and CFS are indeed distinct. Not only do cognitive symptoms form part of the DSM-IV diagnosis of depression but cognitive theories of depression suggest that specific thought processes define the disorder (Beck, 1964). The characteristic cognitive profile of depressed patients includes a negative selfconcept, and themes of loss, abandonment and defeat (Beck, 1964). This negative self-schema is thought to generate a series of distortions in thinking such as selective abstraction - focusing on the negative aspects of an experience, catastrophising - expecting the worst outcome to occur, personalization - seeing oneself as responsible for negative events, and overgeneralizing - assuming the negative consequences of one experience apply to another (Beck, 1964; Beck et al. 1978). These distorted thought processes and negative self-concept distinguish depressed patients from patients with other forms of psychopathology (Mathews \&
MacLeod, 1994). Thus, if CFS is distinct from depression, CFS patients should not report these classic errors of thinking.

Our previous work has shown that CFS patients appear to have a particularly negative view of their illness and to be less likely to attribute their illness to internal factors when compared to patients with other chronic medical conditions (Weinman et al. 1996). They also tend to make catastrophic interpretations of the consequences of their illness (Petrie et al. 1995). Accordingly, we hypothesized that while depressed patients' schema are dominated by negative self-perceptions, CFS patients' perceptions are dominated by their views of themselves as seriously physically ill people. Therefore, we anticipated that while depressed patients would demonstrate negative distorted thinking in a range of situations, CFS patients would only demonstrate these distortions when interpreting somatic information.

Comparing CFS and depressed patients' cognitions may not only help in differentiating the phenomenology of the disorders. Recent models of CFS suggest that patients' cognitions play an important role in maintaining this disorder (Wessely et al. 1991; Surawy et al. 1995). In particular, a precipitating event such as a virus is seen to trigger a cycle of responses whereby patients interpret ongoing symptoms as signs of physical illness. This results in limiting activity levels and the development of cognitions and behavioural responses which are thought to perpetuate the level of disability and fatigue experienced by these patients. To date, the nature of CFS patients' cognitions have largely been documented through clinical observation and there is little empirical evidence to support the unique nature of these belief structures.

Thus, the aims of the current study were as follows. First, to compare the cognitions and behavioural responses of CFS and depressed patients to determine whether these disorders have unique cognitive profiles. In particular, we hypothesized that CFS patients' negative cognitions would be specific to health and illness, that they would have a tendency to view their illness as organic, and to limit their activity levels in order to cope with their illness. Secondly, to investigate whether this cognitive profile remains stable over time and thirdly to determine whether the CFS-related cognitions 
and behavioural responses predict ongoing disability and fatigue in this disorder.

\section{METHOD}

\section{Participants}

Because of the phenomenological overlap between depression and CFS, an important component of this study was ensuring the appropriate allocation to groups. Standardized diagnostic interviews were used in conjunction with self-report measures to confirm patient diagnoses. The CFS group was also divided into those with and those without a concurrent diagnosis of depression, to avoid the possible confounding of dual diagnoses.

\section{CFS group}

The CFS patients were recruited from a general medical practice specializing in the treatment of CFS. Patients aged between 18-65 who were diagnosed by the general practitioner as having CFS, and who provided informed consent to participate in the study were interviewed by one of the investigators. Of the 65 patients who provided informed consent, eight did not meet criteria, and four dropped out of the study.

The diagnostic interview assessed whether patients met current research criteria for CFS (Fukuda et al. 1994) and whether they had a concurrent diagnosis of depression. The interviewer-administered computerized version of the Composite International Diagnostic Interview (CIDI-Auto) (Health, WHO, 1993) was used to diagnose depression as it has been recommended for use in CFS research (Fukuda et al. 1994).
The CIDI-Auto has demonstrated procedural validity against expert clinical diagnoses (Peters \& Andrews, 1993) and the items have good reliability (Wittchen, 1994).

Fourteen $(26 \%)$ of the 53 subjects had a concurrent DSM-III-R diagnosis of major depression or dysthymia, similar to a number of other studies which have identified concurrent depression in CFS (Katon et al. 1991; Bombardier \& Buchwald, 1995). In this study the estimate of depression may have been conservative, as the CIDI excludes somatic symptoms from diagnostic criteria if they have been attributed to physical illness by a medical practitioner. As the role of somatic symptoms in diagnosing depression in CFS is a controversial issue (Ray, 1991), the conservative estimate was deemed preferable. The final sample consisted of 39 CFS patients without depression (CFS) and 14 CFS patients with a concurrent diagnosis of depression (CFS-depressed). Fifty-one per cent of this group belonged to a CFS support group. The demographic details of the two CFS groups together with the comparison groups are presented in Table 1. Analysis of variance (ANOVA) and chi-square tests were used to confirm that the groups were comparable with regard to demographic features.

\section{Depressed group}

Inclusion criteria for the depressed group, included a current primary DSM-III-R diagnosis of major depression or dysthymia, a Beck Depression Inventory (Beck, 1978) score $\geqslant 10$, no evidence of psychosis, organicity, addiction,

Table 1. Characteristics of group participants

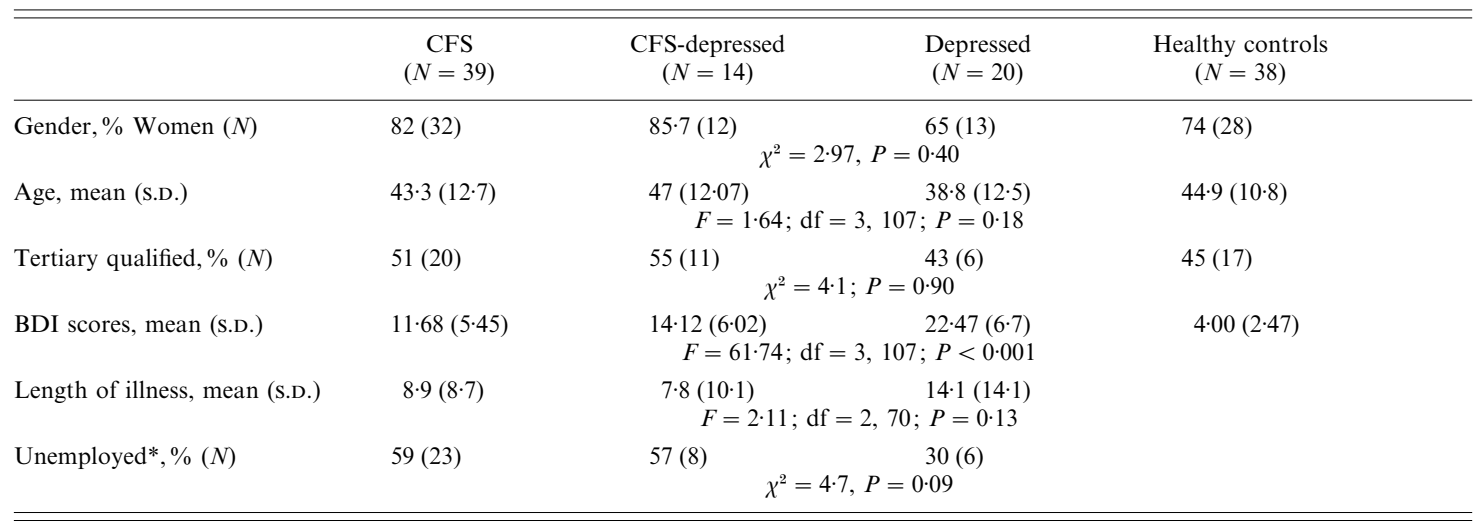

* Unemployment due to illness. 
Table 2. Current and past diagnoses of depression across illness groups

\begin{tabular}{lccc}
\hline \hline & $\begin{array}{c}\text { CFS } \\
(N=39) \\
\%(N)\end{array}$ & $\begin{array}{c}\text { CFS-depressed } \\
(N=14) \\
\%(N)\end{array}$ & $\begin{array}{c}\text { Depressed } \\
(N=20) \\
\%(N)\end{array}$ \\
\hline $\begin{array}{l}\text { Current diagnoses } \\
\text { No diagnosis }\end{array}$ & $100(53)$ & & \\
$\begin{array}{l}\text { Major depression } \\
\text { Dysthymia }\end{array}$ & & $85 \cdot 7(12)$ & $90(18)$ \\
$\begin{array}{l}\text { Past history } \\
\text { No history }\end{array}$ & $14 \cdot 2(2)$ & $10(2)$ \\
Major depression & $52 \cdot 1(16)$ & $14 \cdot 3(2)$ & $10(92)$ \\
Dysthymia & $7.9(3)$ & $78 \cdot 6(11)$ & $85(17)$ \\
\hline \hline
\end{tabular}

or chronic physical illness. To be comparable with the CFS group, the depressed patients needed to be receiving out-patient rather than in-patient treatment and to be between 18- and 65 -years old. Patients were recruited through private psychologists and community mental health centres. Subjects who provided informed consent were interviewed with the CIDI to confirm that they met current criteria for a depressive disorder. Three of 23 patients interviewed did not meet inclusion criteria. The final primary depressed group consisted of two patients with dysthymia and 18 with major depression.

The CIDI data from all three patient groups are presented in Table 2. Most of the CFSdepressed and primary depressed patients met criteria for major depression with only two patients in each group meeting criteria for dysthymia. The majority of the patients had a history of depressive disorders, including $68 \%$ of the non-depressed CFS patients.

Table 1 shows that the mean BDI score for the primary depressed group was in the moderately depressed range (Kendall et al. 1987) and was substantially higher than the scores for the two CFS groups. The means for the CFS groups both fell within the mildly depressed range, although the score for the CFS-depressed group was higher than that of the CFS group.

\section{Control group}

The healthy controls were recruited through the university and the community on the basis that they matched the patient groups as far as possible for the demographic features identified in Table 1. Exclusion criteria were a BDI score $\geqslant 10$, a current or past history of depression or CFS, and/or a current chronic illness. A score $\geqslant 10$ on the BDI is indicative of possible depressive disorder (Beck et al. 1978). Eight of the 46 healthy volunteers scored $>10$ on the BDI resulting in a final sample of 38 healthy controls.

\section{Measures}

Two types of measures were included in this study, those measuring cognitive behavioural factors and those assessing the specific symptom profiles and level of disability of the groups.

The Self-Esteem Scale (Rosenberg, 1995)

This was used to operationalize negative selfschema. It is the most frequently used measure of self-esteem and has good internal reliability, test-retest reliability, and convergent and discriminate validity (Blascovich \& Tomaka, 1991). High scores represent greater self-esteem.

\section{Self-rated health}

Self-rated health was used as a measure of illness schema. It is a widely used single-item measure of individuals' perceptions of themselves as healthy or sick people (Johnston et al. 1995). The Short Form Health Survey version of the scale (Ware \& Sherbourne, 1992) was used in the current study, where low scores represent more healthy perceptions.

\section{Illness Perception Questionnaire (IPQ, Weinman et al. 1996)}

Two subscales of the IPQ were used to measure dimensions of patients' illness beliefs. The illness identity subscale measures the number of somatic symptoms patients associate with their illness. The identity scale in this study consisted of 20 symptoms, including the 12 core IPQ items which are symptoms commonly experienced by the general population and eight additional symptoms commonly reported by depressed and CFS patients (Moss-Morris et al. 1996). The causal subscale measures patients' beliefs about the causes of their illness. For the purpose of this study patients were presented with a list of 18 possible causes of their illness. Half of these were psychological causes such as 'recent stressful events' and 'my mental attitude' while the other half were physical causes such as 'a virus', 'immune dysfunction' or 'a neurochemical imbalance'. Subjects were asked to assign a percentage to each factor, so that the overall assignment of causes equalled $100 \%$. If they 
believed the factor was unrelated to their illness they were asked to assign the factor 0 . Two scores were computed, one which measured the percentage patients assigned to physical causes and the other the percentage assigned to psychological causes.

\section{Cognitive Errors Questionnaire-Revised \\ (CEQ-R, Moss-Morris \& Petrie, 1997)}

The CEQ-R was devised specifically to assess cognitive distortions in this study. The CEQ-R is divided into two subscales: the 12-item General CEQ-R and the 9-item Somatic CEQ$R$. Each of the 21 items describes an everyday situation involving either work, recreation, or family experiences. The general items focus on interpersonal experiences, while the somatic ones include the experience of common symptoms, such as fatigue, aches and pains, and muscle weakness. These vignettes are followed by a thought that a person in that situation may have. For example, one of the general items states; 'You hand in a report to your boss that has taken you four hours to write. Your boss, however, doesn't say anything about it. You think to yourself, " (S)he must think I did a lousy job"'. An example of a somatic item is 'You have been feeling very weak and tired of late, but have continued to work. Although you got quite a bit done today, you finished work early because you were feeling particularly exhausted. You think to yourself, "What a terrible day. It seems like I can't get anything done"'. The thoughts are worded to represent the cognitive errors of catastrophizing, overgeneralizing, personalization, and selective abstraction (Beck et al. 1978). An in depth analysis of this questionnaire which included the current samples showed that the subscales have high internal consistency across groups and good test-retest reliability over 6 months (Moss-Morris \& Petrie, 1997).

\section{Coping}

A three-item measure of limiting coping was included in the questionnaire (Sharpe et al. 1992). Patients were asked the extent to which they limited exercise, activity, and stress in order to cope with their illness on a 4-point scale rated from 'I usually didn't do this at all 'to' I usually did this a lot'. These items have been shown to predict ongoing disability in patients with chronic fatigue (Sharpe et al. 1992).

\section{Symptoms of distress and fatigue}

Two subscales of the Mental Health Inventory (Viet \& Ware, 1983) that discriminate between the somatic and affective components of distress were used to substantiate the symptom differences between the four subject groups. The MHI-5 (Ware et al. 1993) is a measure of the affective dimensions of anxiety, depression, and psychological well-being. It has demonstrated high internal consistency (Ware et al. 1993), and is a valid measure of psychiatric dysfunction (Berwick et al. 1991). The Vitality Scale (Ware et al. 1993) is a 4-item measure of energy and fatigue. The vitality scale has a sound record of empirical validity, item discriminant validity, and scale reliability (Ware \& Sherbourne, 1992). Both of these subscales are scored so that high scores indicate greater psychological well-being and vitality.

\section{Disability}

The Sickness Impact Profile (SIP, Gilson et al. 1979) was used as a measure of sickness related disability. The SIP has been found to be a convincing measure of functional status in a range of chronic illnesses (De Bruin et al. 1992). The questionnaire's validity, test-retest reliability and internal consistency are well established (De Bruin et al. 1992). Because the scale is very lengthy and the reliability and basic construct validity appear to be unaffected by administering only selected subscale categories (Bergner et al. 1981), six subscales were included in the current study. Five of these subscales - social interaction, alertness behaviour, sleep and rest, home management, and recreational pastimes-have been shown to most clearly represent CFS-related disability (Schweitzer et al. 1995). These scores were summed and divided by five to produce a SIP dysfunction score out of 100 . We also included the SIP work subscale as a separate variable as it was only relevant to the percentage of people who were working before their illness.

\section{Procedure}

Items determining the demographic features of the groups and the self-report measures were compiled into a single questionnaire. The IPQ subscales, SIP, and limiting coping scale, which are specific to illness, were included only in the 
patient questionnaires. All participants provided informed consent before they were given a copy of the questionnaire and a self-addressed return envelope. The patient groups also completed a diagnostic interview to determine their eligibility for the study. All subjects were asked to complete the questionnaire within a week and to post it back to the investigators.

Six months after completing the initial questionnaire, participants in the patient groups completed a shortened version of the questionnaire included the MHI-5, Vitality, SIP, Self-Rated Health, CEQ-R and Illness Identity scales. Two of the depressed patients could not be contacted and one depressed patient and two CFS patients did not return the questionnaire. The overall response rate of the follow-up questionnaire was $85 \%$ for the depressed group, $95 \%$ for the CFS group and $100 \%$ for the CFSdepressed group.

\section{RESULTS}

Data analysis was performed on the SPSS version 8.0 computer software program (Norušis, 1993). Results of the evaluation of the assumptions of normality of sampling distributions, linearity, and homogeneity of variance were satisfactory for all of the variables and there were no obvious outliers. A series of Analysis of Variance (ANOVA) were used to test the hypotheses regarding differences between the groups. Due to the large number of planned analyses, a Bonferonni adjusted alpha was used in these equations; $P<0.0045(0 \cdot 05 / 11)$ at time one and $P<0.007(0.05 / 7)$ at time two. To ascertain whether covariates should be included in these equations, correlations were computed between age, gender, level of education, marital status, length of illness, and the various dependent variables (DVs). There were no significant correlations, and as there were no significant differences between the groups on these factors, no covariates were included. Post$h o c$ analyses were conducted with Tukey's test. Stepwise multiple regression was used to investigate the relationships between the cognitive behavioural factors and ongoing disability and fatigue in the CFS group.

\section{Symptoms and disability across groups}

A summary of the ANOVA results from time one are presented in Table 3. The first stage of the analyses involved clarifying the validity of the four groups by comparing their scores on the MHI-5 and Vitality scales. Vitality scores were significantly different between groups. Post-hoc tests suggested that this difference was due to the higher scores for the control group when compared to all three patient groups, who had equivalent scores. MHI-5 scores also differed, with post-hoc analyses suggesting a number of significant contrasts between the four groups. As with the Vitality scale, healthy controls scored significantly higher on the MHI-5 than all the patient groups. CFS non-depressed patients also scored significantly higher than both the depressed groups and CFS-depressed patients scored higher than primary depressed patients.

Table 3. Analysis of variance of the self-report measures at Time 1

\begin{tabular}{|c|c|c|c|c|c|c|}
\hline & $\begin{array}{c}\text { CFS } \\
\text { Mean (S.D.) }\end{array}$ & $\begin{array}{c}\text { CFS-depressed } \\
\text { Mean (S.D.) }\end{array}$ & $\begin{array}{c}\text { Depressed } \\
\text { Mean (S.D.) }\end{array}$ & $\begin{array}{c}\text { Controls } \\
\text { Mean (S.D.) }\end{array}$ & df & $F$ \\
\hline Vitality & $26 \cdot 54(18 \cdot 54) \dagger$ & $20 \cdot 71(18.69) \dagger$ & $26.50(14.96) \dagger$ & $68 \cdot 69(15 \cdot 14)$ & 3,107 & $55 \cdot 46^{*}$ \\
\hline MHI-5 & $68 \cdot 10(15 \cdot 60) \dagger 末$ & $47 \cdot 43(3 \cdot 75) \dagger+\S$ & $36.40(15.57) \dagger$ & $79 \cdot 58(10 \cdot 26)$ & 3,107 & $51 \cdot 05^{*}$ \\
\hline SIP dysfunction & $42 \cdot 17(13 \cdot 79)$ & $47 \cdot 59(14 \cdot 14)$ & $44 \cdot 82(13 \cdot 82)$ & & 2,67 & $0 \cdot 83$ \\
\hline SIP work & $58 \cdot 48(17 \cdot 48)$ & $59 \cdot 69(33 \cdot 64)$ & $52 \cdot 29(24 \cdot 94)$ & & 2,54 & \\
\hline Self-esteem & $31 \cdot 25(4 \cdot 73)$ & $27 \cdot 71(5 \cdot 67) \dagger \S$ & $24 \cdot 86(5 \cdot 76) \dagger \S$ & $33 \cdot 11(4 \cdot 12)$ & 3,107 & $14 \cdot 85^{*}$ \\
\hline Self-rated health & $4.05(0.79) \dagger+$ & $4.00(0.96) \dagger+$ & $3 \cdot 15(1 \cdot 14)$ & $1.76(0.68)$ & 3,107 & $52 \cdot 86^{*}$ \\
\hline General CEQ-R & $21.69(8.99)+$ & $26.03(7.79)+$ & $35 \cdot 15(11.85) \dagger$ & $21 \cdot 47(6 \cdot 58)$ & 3,107 & $10 \cdot 66^{*}$ \\
\hline Somatic CEQ-R & $21.79(8 \cdot 16) \dagger$ & $21 \cdot 36(6 \cdot 22) \dagger$ & $23 \cdot 24(9 \cdot 1) \dagger$ & $14.83(4 \cdot 65)$ & 3,107 & $12 \cdot 97^{*}$ \\
\hline Somatic illness identity & $17 \cdot 59(2 \cdot 20)+$ & $18 \cdot 21(2 \cdot 33) \div$ & $13 \cdot 40(3 \cdot 94)$ & & 2,70 & $17 \cdot 82^{*}$ \\
\hline Psychological attributions & $25 \cdot 39(24.99)$ & $17 \cdot 86(21 \cdot 81)$ & $62 \cdot 13(23 \cdot 42)$ & & 2,68 & $19 \cdot 31^{*}$ \\
\hline Physical attributions & $62 \cdot 11(28.62) \ddagger$ & $77 \cdot 86(21 \cdot 81)+$ & $15 \cdot 90(16 \cdot 12)$ & & 2,68 & $31 \cdot 04^{*}$ \\
\hline Limiting coping & $9 \cdot 87(1.80) \$$ & $8.79(2.61) \ddagger$ & $7 \cdot 05(2 \cdot 48)$ & & 2,70 & $11 \cdot 04^{*}$ \\
\hline
\end{tabular}

* $P<0.0045$

$\dagger$ Significantly different from the control group.

+ Significantly different from the depressed group.

$\S$ Significantly different from the CFS group. 
The ANOVA of the SIP data showed there were no differences in the level of sickness related disability reported by all three groups. Thus, in terms of presentation, CFS and depressed patients appear to report equivalent levels of energy loss and disability. Depressed patients however report higher levels of negative mood than do CFS patients.

\section{Cognitive behavioural factors across groups}

$$
\text { Self-esteem }
$$

Comparisons confirmed that the two depressed groups had significantly lower self-esteem than the CFS non-depressed and healthy control groups. There were no significant differences between the two depressed groups, or between the CFS non-depressed and healthy control groups.

\section{Self-rated health}

The ANOVA for self-rated health showed that both CFS groups rated themselves as significantly less healthy than depressed patients and controls. In turn, the depressed group also rated themselves as less physically healthy than controls.

\section{Illness beliefs}

Both CFS groups showed a significantly stronger somatic illness identity as they endorsed a higher number of physical symptoms to their illness than did depressed patients. There was no differences between the two CFS groups on this measure. Similarly, the two CFS groups made significantly more physical attributions and significantly fewer psychological attributions for their illness than did depressed patients.

\section{Cognitive distortions}

To assess whether level and type of cognitive distortion varied with group membership, the two subscales of the CEQ-R were entered into two separate ANOVA equations. There was a highly significant difference for group on both subscales. Post-hoc analyses revealed that the depressed group scored significantly higher than all the other three groups on the General CEQ$\mathrm{R}$. There was no difference between the two CFS groups and healthy controls on this subscale. However, all three patient groups scored significantly higher on the somatic CEQ-R when compared with healthy controls.

\section{Coping}

As predicted, both CFS groups were more likely to deal with their illness by limiting activity and stress than were the depressed group. There was no difference on this measure between the CFS groups.

\section{Stability of cognitions over 6 months}

Identical analyses were conducted on the measures included in the second questionnaire. Table 4 shows that there was almost no change in the pattern of results. The three groups were still indistinguishable on measures of vitality and sickness-related disability. Both the depressed groups scored lower on psychological well-being (MHI-5) than did the CFS group. However, unlike at time one, the CFS-depressed group did not score significantly higher than the depressed group on this scale. Both of these groups scored higher on this scale than at time one, suggesting that their mood had improved over the 6-month period.

The prototype of cognitive differences was unchanged. The CFS groups rated themselves as less healthy and experiencing more physical symptoms as part of their illness. The depressed group scored higher on the General CEQ-R but not the Somatic CEQ-R. Interestingly, although the groups showed improvements in their levels of disability and symptom reports over the 6month period, within-group analyses showed that there were no significant changes in scores on the CEQ-R subscales in either of the groups. For the CFS group the results of the paired samples $t$ tests on Somatic CEQ-R were $t=0.83$ (50) $P=0.41$ and on the General CEQ-R, $t=$ -0.74 (50) $P=0.46$. For the depressed group the results on the Somatic CEQ-R were $t=$ $-0 \cdot 16(16) P=0.88$ and on the General CEQ$\mathrm{R}, t=0.47$ (16) $P=0.64$.

\section{Cognitive-behavioural variables and ongoing disability and fatigue in CFS}

Three separate stepwise regression equations were used to investigate the relationships between the CFS-related cognitive-behavioural factors measured at time one, and disability and fatigue measured 6 months later in the CFS group. The dependent variables included the Vitality scale as a measure of fatigue and the two 
Table 4. Analysis of variance of the self-report measures at 6 months follow-up

\begin{tabular}{|c|c|c|c|c|c|}
\hline & $\begin{array}{c}\text { CFS } \\
\text { Mean (S.D.) }\end{array}$ & $\begin{array}{c}\text { CFS-depressed } \\
\text { Mean (S.D.) }\end{array}$ & $\begin{array}{c}\text { Depressed } \\
\text { Mean (S.D.) }\end{array}$ & df & $F$ \\
\hline Vitality & $30 \cdot 14(21 \cdot 97)$ & $30 \cdot 36(18 \cdot 76)$ & $41 \cdot 18(18 \cdot 50)$ & 2,65 & $1 \cdot 82$ \\
\hline MHI-5 & $69 \cdot 62(13 \cdot 77)$ & $56.57(15 \cdot 11) \neq$ & $52 \cdot 00(25 \cdot 38)+$ & 2,65 & $6 \cdot 85^{*}$ \\
\hline SIP dysfunction & $37 \cdot 03(17 \cdot 87)$ & $37 \cdot 50(17 \cdot 05)$ & $26 \cdot 93(16 \cdot 21)$ & 2,65 & $2 \cdot 27$ \\
\hline SIP work & $46 \cdot 95(26 \cdot 18)$ & $34 \cdot 80(28 \cdot 32)$ & $41 \cdot 03(25 \cdot 71)$ & 2,53 & $1 \cdot 04$ \\
\hline Self-rated health & $3.59(0.83) \dagger$ & $3.71(0.83) \dagger$ & $2 \cdot 76(0.90)$ & 2,65 & $6.67^{*}$ \\
\hline General CEQ-R & $22 \cdot 84(11 \cdot 53) \dagger$ & $24 \cdot 71(9 \cdot 29) \dagger$ & $33 \cdot 29(11 \cdot 11)$ & 2,65 & $5 \cdot 34 *$ \\
\hline Somatic CEQ-R & $21 \cdot 65(9 \cdot 10)$ & $22 \cdot 50(4 \cdot 60)$ & $23.49(9.66)$ & 2,65 & $0 \cdot 27$ \\
\hline Somatic illness identity & $17.03(4.54) \dagger$ & $17 \cdot 00(3 \cdot 38) \dagger$ & $9 \cdot 50(6 \cdot 10)$ & 2,65 & $17 \cdot 64 *$ \\
\hline
\end{tabular}

$* P<0.007$.

$\dagger$ Significantly different from the depressed group.

$\$$ Significantly different from the CFS group.

SIP variables, general dysfunction and work disability.

In each of the equations, age and length of illness were entered as independent variables together with physical attributions, somatic illness identity, the Somatic CEQ-R, and limiting coping. For vitality, both somatic illness identity and age entered the equation and accounted for a unique $21 \%$ of the variance, $F(1,41)=12 \cdot 52$, $P<0 \cdot 001)$. Somatic illness identity was the strongest predictor $(\beta=-0.48, P<0.001)$ followed by age $(\beta=0 \cdot 31, P<0 \cdot 05)$. Somatic illness identity $(\beta=-0.61, P<0.001)$ and the Somatic CEQ-R $(\beta=0 \cdot 26, P<0 \cdot 05)$ were the only significant predictors of dysfunction. Together these variables accounted for $38 \%$ of the variance in dysfunction, $F(1,41)=24 \cdot 60$, $P<0.001$. Somatic illness identity $(\beta=0.56$, $P<0.001$ ) was once again the first variable to enter the equation for work dysfunction with limiting coping $(\beta=0.51, P<0.001)$ also a significant predictor. Taken together these two variables accounted for a unique $24 \%$ of the variance in work dysfunction, $F(1,32)=10 \cdot 32$, $P<0 \cdot 01$.

\section{DISCUSSION}

The results generally supported the hypothesis that depressed patients' self-schema are dominated by a negative view of the self, while CFS patients are primarily concerned with their poor health. Both depressed groups had lower selfesteem than healthy controls and CFS nondepressed patients, while both CFS groups rated themselves as significantly less healthy than the other two groups. The primary depressed group's ratings of health lay midway between those of controls and the CFS groups.
The symptom profiles of each of the patient groups to some extent reflected the differences in these self-schemas. The groups were clearly delineated on the affective dimension of psychological well-being with the primary depressed patients being the most distressed and the healthy controls the least distressed. CFS patients fell in between these groups with the CFS-depressed patients reporting more distress than the non-depressed ones. The three patient groups were indistinguishable on the somatic dimension of distress, with all three groups reporting substantially lower levels of vitality than healthy controls.

With regard to illness beliefs, there were no differences between the two CFS groups, but substantial differences between CFS and depression. In accordance with previous research, CFS patients made significantly more physical attributions but fewer psychological attributions for their illness than did depressed patients (Powell et al. 1990). Both CFS groups also ascribed a significantly larger number of somatic symptoms to their illness than did the depressed group. While this difference may merely reflect the physical status of the CFS patients there are arguments against this possibility. Earlier work has shown that CFS patients ascribe a larger number of somatic symptoms of their illness than do patients with other chronic medical conditions (Weinman et al. 1996). In the current study, out of a total of 20 symptoms, the CFS patients on average reported experiencing 18 as a result of their illness. While some of these symptoms such as fatigue and muscle pain are characteristic of CFS, others such as pins-andneedles and sore eyes are symptoms commonly experienced in the population as a whole. This 
suggests that CFS patients may misattribute common symptoms to their illness.

CFS patients' preoccupation with their symptoms rather than with their sense of self is also reflected in the CEQ-R data. CFS patients only displayed distorted thinking in situations where they might experience symptoms and not in general interpersonal situations. Concurrent depression did not appear to alter this pattern of thinking. Only the depressed group could be distinguished from the healthy controls on the tendency to distort the meaning of interpersonal situations. It is interesting that although the depressed patients do not view their health as negatively as the CFS group, and do not respond to their illness by limiting stress and activity to the same extent, they have a similar tendency to report somatic errors in thinking. For this group, somatic errors may be reflective of a generalized tendency to see the world in a negative fashion.

The differences between CFS and depression were maintained over the 6 month period. There were no significant changes in the scores on either the Somatic or General CEQ-R, suggesting that these may be relatively stable thought processes or ways of viewing the world. It is also worth noting that CFS-depressed patients showed greater overlap with CFS patients than with primary depressed patients at both time points.

In support of the cognitive behavioural models, the CFS-related cognitive behavioural factors predicted ongoing disability and fatigue in this group, even when controlling for age and length of illness. Somatic illness identity was the most significant predictor of both ongoing dysfunction and fatigue. Coping by limiting stress and activity was associated with workrelated dysfunction, while somatic cognitive errors were associated with disability in the other domains. Interestingly, consistent with previous work in this area (Moss-Morris et al. 1996; Heijmans \& de Ridder, 1998), physical attributions which are one of the key defining features of the illness, failed to predict outcome in this group. Changes in physical attributions also fail to predict successful outcome in CFS patients following cognitive behavioural therapy (Deale et al. 1998). These results suggest that therapy approaches which assist CFS patients to reinterpret the meaning of their symptoms in conjunction with exploring coping responses, which encourage rather than limit activity, may help to alleviate some of the negative disabling effects of the illness. It may be particularly important to explore alternative labels for symptoms. For instance, some of the somatic symptoms patients attribute to their CFS could be re-labelled as signs of deconditioning, while others such as headaches could be attributed to stress. It appears to be less important to alter patients' beliefs that their illness is caused by physical factors. This factor may in fact be adaptive in that it may help to maintain a healthy self-esteem.

Taken together, the results of this study are consistent with a growing body of evidence that argues against CFS being a version of depression. It also provides some support for the role cognitions and behaviour play in the maintenance of CFS. However, a limitation of the current study was the small sample sizes and the convenience sampling method make it difficult to generalize the results to all CFS and depressed patients. It is also difficult to confirm the directional links of these models from this comparative study. It is possible that the cognitive profile in CFS is a reflection of the fact that these patients have a serious ongoing physical illness. However, two findings argue against this possibility. First, CFS patients appear to have even more negative views of their illness than do patients with other chronic physical illnesses and these beliefs are associated with ongoing disability and fatigue. Secondly, although numerous physiological abnormalities have been documented in CFS, these are seldom associated with the magnitude of the symptoms experienced by CFS patients (Wessely, 1996). Prospective research in this area and studies that compare CFS patients to patients with other physical illnesses could help to address the nature of CFS patients' cognitions further.

This research was supported by the Health Research Council of New Zealand.

\section{REFERENCES}

Abbey, S. E. (1996). Psychiatric diagnostic overlap in chronic fatigue syndrome. In Chronic Fatigue Syndrome: An Integrated Approach to Evaluation and Treatment (ed. M. A. Demitrack and S. E. Abbey), pp. 49-71. Guilford Press: New York.

Beck, A. T. (1964). Thinking and depression: II. Theory and therapy. Archives of General Psychiatry 10, 561-571. 
Beck, A. T. (1978). Depression Inventory. Centre for Cognitive Therapy: Philadelphia.

Beck, A. T., Rush, A. J., Shaw, B. F. \& Emery, G. (1978). Cognitive Therapy of Depression: A Treatment Manual. AT Beck: Philadelphia.

Bergner, M., Bobbitt, R. A., Carter, W. B. \& Gilson, B. S. (1981). The Sickness Impact Profile: validation of a health status measure . Medical Care 19, 787-805

Berwick, D. M., Murphy, J. M., Goldman, P. A., Ware, J. E., Barsky, A. J. \& Weinstein, M. C. (1991). Performance of a fiveitem mental health screening test. Medical Care 29, 169-176.

Blascovich, J. \& Tomaka, J. (1991). Measures of self esteem. In Measures of Personality and Social Psychological Attitudes (ed. J. P. Robinson, P. R. Shaver and L. S. Wrightsman), pp. 115-128. Harcourt Brace Jovanovich: San Diego.

Bombardier, C. H. \& Buchwald, D. (1995). Outcome and prognosis in patients with chronic fatigue and chronic fatigue syndrome. Archives of Internal Medicine 155, 2105-2110.

Cleare, A. J., Bearn, J., Allain, T., McGregor, A., Wessely, S., Murray, R. M. \& O'Keane, V. (1995). Contrasting neuroendocrine responses in depression and chronic fatigue syndrome. Journal of Affective Disorders 34, 283-289.

De Bruin, A. F., De Witte, L. P., Stevens, F. \& Diedericks, J. P. M. (1992). Sickness impact profile: the state of the art of a generic functional status measure. Social Science and Medicine $\mathbf{3 5}$, 1003-1014.

Deale, A., Chalder, T. \& Wessely, S. (1998). Illness beliefs and treatment outcome in chronic fatigue syndrome. Journal of Psychosomatic Research 45, 77-83.

Evengard, B., Schacterle, R. S. \& Komoroff, A. L. (1999). Chronic fatigue syndrome: new insights and old ignorance. Journal of Internal Medicine 246, 255-469.

Fischler, B., D'Haenen, H., Cluydts, R., Michiels, V., Demets, K., Bossuyt, A., Kaufman, L. \& De Meirleir, K. (1996). Comparison of $99 \mathrm{~m}$ Tc HMPAO SPECT scan between chronic fatigue syndrome, major depression and healthy controls: an exploratory study of clinical correlates of regional cerebral blood flow. Neuropsychobiology 34, 175-183.

Fukuda, K., Straus, S. E., Hickie, I., Sharpe, M. C., Dobbins, J. G. \& Komaroff, A. (1994). The chronic fatigue syndrome: a comprehensive approach to its definition and study. International Chronic Fatigue Syndrome Study Group. Annals of Internal Medicine 121, 953-959.

Gilson, B. S., Bergner, M., Bobbit, R. A. \& Carter, W. B. (1979). The Sickness Impact Profile: Final Development and Testing. University of Washington, Department of Health Services: Seattle.

Goldstein, J., Mena, I., Jouanne, E. \& Lesser, I. (1995). The assessment of vascular abnormalities in late life chronic fatigue syndrome by brain SPECT: comparison with late life major depressive disorder. Journal of Chronic Fatigue Syndrome 1, 55-79.

Health, WHO (1993). World Health Organization Composite International Diagnostic Interview: CIDI-Auto version 1.1. St. Vincent's Hospital: Sydney.

Heijmans, M. \& de Ridder, D. (1998). Assessing illness representations of chronic illness: explorations of their disease-specific nature. Journal of Behavioral Medicine 21, 485-503.

Hickie, I., Lloyd, A., Wakefield, D. \& Parker, G. (1990). The psychiatric status of patients with the chronic fatigue syndrome. British Journal of Psychiatry 156, 534-540.

Johnson, S. K., Deluca, J. \& Natelson, B. H. (1996). Depression in fatiguing illness-comparing patients with chronic fatigue syndrome, multiple sclerosis and depression. Journal of Affective Disorders 39, 21-30.

Johnston, M., Wright, S. \& Weinman, J. (1995). Measures in Health Psychology: A User's Portfolio. NFER-Nelson: Windsor.

Katon, W. J., Buchwald, D. S., Simon, G. E., Russo, J. E. \& Mease, P. J. (1991). Psychiatric illness in patients with chronic fatigue and those with rheumatoid arthritis. Journal of General Internal Medicine 6, 277-285.

Kendall, P. C., Hollon, S. D., Beck, A. T., Hammen, C. L. \&
Ingram, R. E. (1987). Issues and recommendations regarding the use of the Beck Depression Inventory. Cognitive Therapy and Research 11, 289-299.

Komaroff, A. L. \& Buchwald, D. (1991). Symptoms and signs of chronic fatigue syndrome. Reviews of Infectious Diseases 13, S8-S11.

Manu, P., Lane, T. J. \& Mathews, D. A. (1993). Chronic fatigue and chronic fatigue syndrome: Clinical epidemiology and aetiological classification. In Chronic Fatigue Syndrome, Ciba Foundation Symposium, Vol. 173 (ed. E. Bock and J. Whelan), pp. 23-42. John Wiley: Chichester.

Mathews, A. \& MacLeod, C. (1994). Cognitive approaches to emotion and emotional disorders. Annual Review of Psychology $\mathbf{4 5}$, $25-50$.

Moss-Morris, R. \& Petrie, K. J. (1997). Cognitive distortions of somatic experiences - revision and validation of a measure. Journal of Psychosomatic Research 43, 293-306.

Moss-Morris, R., Petrie, K. J. \& Weinman, J. (1996). Functioning in chronic fatigue syndrome: do illness perceptions play a regulatory role. British Journal of Health Psychology 1, 15-25.

Natelson, B. H., Cheu, J., Pareja, J., Ellis, S. P., Policastro, T. \& Findley, T. W. (1996). Randomized, double blind, controlled placebo-phase in trial of low dose phenelzine in the chronic fatigue syndrome. Psychopharmacology 124, 226-230.

Norušis, M. J. (1993). SPSS for WindowsTM Professional Statistics TM Release 6.0. SPSS Inc: Chicago.

Pepper, C., Krupp, L., Friedberg, F., Doscher, C. \& Coyle, P. (1993). A comparison of neuropsychiatric characteristics in chronic fatigue syndrome, multiple sclerosis and major depression. Journal of Neuropsychiatry Clinical Neurosciences 5, 200-205.

Peters, L. \& Andrews, G. (1993). Reprocedural validity of the CIDIAuto. Unit report 93/2. Clinical Research Unit for Anxiety Disorders: Sydney.

Petrie, K. J., Moss-Morris, R. \& Weinman, J. (1995). Catastrophic beliefs and their implications in the chronic fatigue syndrome. Journal of Psychosomatic Research 39, 31-37.

Powell, R., Dolan, R. \& Wessely, S. (1990). Attributions and selfesteem in depression and chronic fatigue syndromes. Journal of Psychosomatic Research 34, 665-73.

Ray, C. (1991). Chronic fatigue syndrome and depression: conceptual and methodological ambiguities. Psychological Medicine 21, 1-9.

Rosenberg, M. (1995). Society and the Adolescent Self-Image. Princeton University Press: Princeton, NJ.

Schwartz, R. B., Komaroff, A. L., Garada, B. M., Gleit, M., Doolittle, T. H., Bates, D. W., Vasile, R. G. \& Holman, B. L. (1994). SPECT imaging of the brain: comparison of findings in patients with chronic fatigue syndrome, AIDS dementia complex, and major unipolar depression. American Journal of Roentgenology 162, 943-951.

Schweitzer, R., Kelly, B., Foran, A., Terry, D. \& Whiting, J. (1995). Quality of life in chronic fatigue syndrome. Social Science and Medicine 41, 1367-1372.

Sharpe, M., Hawton, K., Seagroatt, V. \& Pasvol, G. (1992). Follow up of patients presenting with fatigue to an infectious diseases clinic. British Medical Journal 305, 147-152.

Surawy, C., Hackmann, A., Hawton, K. \& Sharpe, M. (1995). Chronic fatigue syndrome: a cognitive approach. Behaviour Research and Therapy 33, 535-44.

Vercoulen, J., Swanink, C. M. A., Zitman, F. G., Vreden, S. G. S., Hoofs, M. P. E., Fennis, J. F. M., Galama, J. M. D., Vandermeer, J. W. M. \& Bleijenberg, G. (1996). Randomised, double-blind, placebo-controlled study of fluoxetine in chronic fatigue syndrome. Lancet 347, 858-861.

Viet, C. T. \& Ware, J. E. (1983). The structure of psychological distress and well-being in general populations. Journal of Consulting and Clinical Psychology 51, 730-742.

Ware, J. E. \& Sherbourne, C. D. (1992). The MOS 36-item shortform health survey. Medical Care 30, 473-483.

Ware, J. E., Snow, K. K., Kosinski, M. A. \& Gandek, B. (1993). SF36 Health Survey: Manual and Interpretation Guide. The Health Institute: Boston. 
Weinman, J., Petrie, K. J., Moss-Morris, R. \& Horne, R. (1996). The Illness Perception Questionnaire-a new method for assessing the cognitive representation of illness. Psychology and Health 11, $431-445$.

Wessely, S. (1996). Chronic fatigue syndrome. Summary of a report of a joint committee of the Royal Colleges of Physicians, Psychiatrists and General Practitioners. Journal of the Royal College of Physicians of London 30, 497-504.

Wessely, S. \& Powell, R. (1989). Fatigue syndromes: a comparison of chronic 'postviral' fatigue with neuromuscular function. Journal of Neurology, Neurosurgery, and Psychiatry 52, 940-948.
Wessely, S., Butler, S., Chalder, T. \& David, A. (1991). The cognitive behavioural management of the post-viral fatigue syndrome. In Postviral Fatigue-Syndrome (ed. R. J. Mowbrey and J. Mowbrey), pp. 305-334. John Wiley \& Sons: Chichester.

Wittchen, H. U. (1994). Reliability and validity studies of the WHOComposite International Diagnostic Interview (CIDI): a critical review. Journal of Psychiatric Research 28, 57-84.

Wood, G. C., Bentall, R. P., Göpfert, M. \& Edwards, R. H. T. (1991). A comparative psychiatric assessment of patients with chronic fatigue syndrome and muscle disease. Psychological Medicine 21, 619-628. 